\title{
An iron isotope perspective on magmatic processes in the Rum Layered Suite
}

\author{
CAPUCINE ALBERT ${ }^{1,2}$, BRIAN O'DRISCOLL ${ }^{3}$ AND \\ HELEN M WILLIAMS ${ }^{1}$ \\ ${ }^{1}$ University of Cambridge \\ ${ }^{2}$ Cardiff University \\ ${ }^{3}$ University of Manchester \\ Presenting Author: capucine.albert@gmail.com
}

The $\sim 60$ Ma Rum layered intrusion in Scotland is the solidified remnant of an open magmatic system. It has traditionally been interpreted as preserving the crystallization products of multiple batches of primitive picritic-basaltic liquid, represented by the juxtaposition of coupled peridotite-gabbro macro-rhythmic units. However, this simplified stratigraphic arrangement disguises a more complex and sustained postcumulus crystallization history, and identifying the signature of magma replenishment events and their discrete effects on the solidifying cumulates is often challenging.

Recent studies have shown textural and geochemical evidence for local compositional disequilibrium across the horizons of magma replenishment, including small-scale mineral chemical and isotopic zoning. The latter signatures have been attributed to infiltration metasomatism and varying degrees of re-equilibration with evolved interstitial melt in the crystal mush $[1,2]$. This, along with very large mineral chemical and isotopic variations often observed over single thin section length-scales in Rum materials suggests a complex interplay of source heterogeneity and crystallization processes, likely hindered by melt percolation and diffusive exchange. New tools are required to trace these processes, which critically need to distinguish between geochemical equilibrium and disequilibrium.

Iron $(\mathrm{Fe})$ stable isotopes may help shed light on this problem, because they are expected to respond to mineral-specific partitioning effects at equilibrium, resulting in resolvable intermineral fractionations even at high temperature [3]. We use Fe isotope data for olivine and $\mathrm{Cr}$-spinel in well-characterised gabbros and peridotites from two sites of new magma replenishment in the Rum intrusion to investigate its postcumulus evolution. Establishing whether there are departures from the predicted equilibrium inter-mineral $\delta^{56} \mathrm{Fe}$ fractionation will give us a way to check if and where minerals record isotopic disequilibrium. This, in turn, will allow us to test whether and to what extent the mineral assemblage was modified during the solidification of the crystal mush, and/or if minerals retain a primary chemical signature.

[1] O'Driscoll et al. (2010), J Pet 51(6), 1171-1201; [2] Hepworth et al. (2020), Nat Geosci 13, 375-381; [3] Macris et al. (2015) GCA, 154, 168-185 